\title{
SYNOPSES
}

\section{PENSION ILLUSTRATIONS- A FAIR COMPARISON OR A CONFIDENCE TRICK}

\author{
BY E. SHORT \\ (Synopsis of a paper presented to the Society on 18 October 1988)
}

THE paper is concerned with investigating how the provision of pension information has developed in the light of the aims set out in the White Paper that preceded the Social Security Act 1986 with particular reference to quotations, illustrations and projections to see whether employees have enough information to make a fair comparison. In particular the paper analyses whether the financial services legislation has removed the use of misleading projections.

The paper considers the purposes of life company illustrations and the alternatives of monetary and real value bases. Five principles that should guide the preparation of illustrations and the provision of information are developed, namely:

- The illustrations must be readily understood by the employee.

- The illustration should not set out misleading information, even if it is apparently understood by the employee.

- The various types of illustration should be prepared on a consistent basis with consistent assumptions.

- The illustrations should focus on providing information that assists the employee in planning an adequate pension.

-The illustration should help the employee differentiate between the various alternative arrangements and various investment media.

Five examples of illustrations are examined to determine the extent to which they satisfy these principles. These cover benefit illustrations for the State Scheme, an Occupational Scheme, a Personal Pension, a non investment (Building Society) personal pension, and a contracted out Money Purchase scheme.

As a result of these comparisons it is concluded that the illustrations give no help at all to employees assessing the merits of company schemes and personal pensions, though they do help in deciding between SERPS and Personal Pensions. This failure arises from three outstanding features:

-Lack of cohesion over the methods used for the illustrations.

- Lack of consistency in the underlying assumptions.

- The illustrations make no attempt to compare like-with-like concerning the totality of benefits provided.

Finally some suggestions are made of ways in which illustrations might be made more meaningful. 